УДК 616.831.31-009.24

DOI 10.11603/1811-2471.2019.v0.i1.10040

\title{
СИМПТОМАТИЧНА ЕПІЛЕПСІЯ: ПРИЧИНИ ВИНИКНЕННЯ ТА ПЕРСПЕКТИВНІ МЕТОДИ ЛІКУВАННЯ
}

\author{
Інститут фізіології імені О. О. Богомольця Національної академії наук України, Київ \\ Неврологічна клініка доктора Яценко, Київ
}

РЕзЮМЕ. Епілепсія - один із найпоширеніших психоневрологічних розладів функціонування ЦНС, що характеризується повторюваними спонтанними епілептичними нападами. Міжнародна протиепілептична ліга визначає епілепсію як хронічний стан мозку, який характеризується стійкою схильністю викликати епілептичні напади і нейробіологічними, когнітивними, психологічними та соціальними наслідками, а також визначення епілепсії вимагає виникнення хоча 6 одного епілептичного нападу. Поліетіологічність та незвичайна різноманітність клінічних проявів епілепсії визначають труднощі в створенні її класифікації. Незважаючи на значні наукові досягнення в неврології, епілепсія залишається значною медико-соціальною проблемою та досі немає відповідей на ключові питання про механізми епілептичних нападів. Триває пошук оптимального лікування, яке 6 покращувало загальний стан хворого на епілепсію, а також допомогло мінімізувати інші, часто шкідливі, наслідки для соціальної адаптації такої людини.

Мета - проаналізувати сучасні погляди на проблему симптоматичної епілепсії та перспективні стратегії її лікування.

Висновок. Результати сучасних досліджень симптоматичної епілепсії розкривають низку напрямків і можливостей для корекції та лікування цієї патології. Одним з перспективних та ефективних методів зниження частоти судомних нападів і покращення електроенцефалографічної картини у хворих на симптоматичну епілепсію може бути така терапевтична технологія, як транскраніальна мікрополяризація. Додавання методу мікрополяризації у комплексне лікування хворих на епілепсію сприяє покращенню електроенцефалографічної картини і, відповідно, позитивно впливає на клінічний перебіг захворювання. Подальші дослідження необхідні для визначення безпечних та ефективних терапевтичних засобів, які застосовуються для лікування симптоматичної епілепсії.

КлючОВІ СЛОВА: симптоматична епілепсія; транскраніальна мікрополяризація.

Вступ. Епілепсія характеризується виникненням ненормальної електричної активності в головному мозку. Вона достатньо часто трапляється в дитячому та підлітковому віці. Епілептичні напади у дитячому віці приблизно в 30 \% випадків призводять до розвитку хронічної епілепсії [30].

Погляди на природу епілепсії еволюціонували від сприйняття її як «демонічної», «священної» «божественної» хвороби до затвердження епілепсії як окремої нозологічної одиниці [14]. Досить тривалий час епілепсію вважали психічним захворюванням $з$ прогредієнтним перебігом і наростаючими змінами психіки [24, 36]. у 1985 р. епілепсія вже характеризувалася як складний комплекс симптомів, при якому психічні розлади тісно переплітаються з неврологічними і соматичними проявами [36]. У 2005 році Міжнародна протиепілептична ліга (International League Against Epilepsy - ILAE) дала визначення епілепсії: «Хронічний стан мозку, який характеризується стійкою схильністю викликати епілептичні напади і нейробіологічними, когнітивними, психологічними та соціальними наслідками. Визначення епілепсії вимагає виникнення хоча 61 епілептичного нападу» $[13,33]$. І лише в 2014 р. епілепсія визнана не розладом, а хворобою головного мозку, тобто затверджено її нозологічну сутність [2].
Основна частина. Загальноприйнятим критерієм епілепсії $\epsilon$ повторювані епілептичні напади, що виникають у результаті порушення процесів гальмування і збудження в нейронах головного мозку [13]. Одиночні, або випадкові, епілептичні напади не розглядаються як епілепсія, а $\epsilon$ різновидом реакції мозку при зниженні порога судомної готовності. Основною причиною виникнення епілепсії $€$ наявність патологічного вогнища активності нейронів головного мозку з пароксизмальними розрядами. За локалізацією епілептичні напади поділяють на фокальні та генералізовані. Фокальний епілептичний напад визначається як напад, що виходить із ділянки нейронних мереж, обмеженої однією півкулею; ця зона може бути локальною або займати більшу площу. Можливе поширення на сусідні зони або перехід на контралатеральну півкулю [9]. Генералізований епілептичний напад визначається як напад, що виходить із деякої ділянки головного мозку, з швидким поширенням і білатеральним захопленням нейронних мереж [13].

Різні типи епілепсії зумовлені різними причинами. Залежно від причини, розрізняють такі види епілепсії: 1) симптоматична, що спричинена наявністю органічного пошкодження нервової тканини внаслідок первинного захворювання; 2) ідіо- 
Огляди літератури, оригінальні дослідження, погляд на проблему, ювілеї

патична, яка виникає без явних причин у певному віці і найчастіше має спадковий характер; 3) криптогенна, що має нез'ясований характер.

До XIX століття симптоматичну епілепсію (раніше відому як органічна епілепсія) взагалі не вважали "справжньою епілепсією". 3 середини XX століття всі або майже всі епілепсії відносили до симптоматичних - у тому сенсі, що епілепсію вважали симптомом захворювання, навіть якщо причину захворювання не завжди можна було визначити [36].
До основних причин симптоматичної епілепсії належать черепно-мозкові травми, цереброваскулярні захворювання, нейроінфекції, перинатальні ураження головного мозку, хромосомні синдроми, метаболічно-гіпоксичні розлади, нейродегенеративні захворювання і пухлини мозку [29]. Поліетіологічність та незвичайна різноманітність клінічних проявів епілепсії визначають труднощі в створенні класифікації. Залежно від причин виникнення симптоматичної епілепсії пропонується така класифікація (табл. 1).

Таблиця 1. Етіологічна класифікація симптоматичної епілепсії*

\begin{tabular}{|c|c|c|}
\hline Етіологія & Підкатегорія & Приклади \\
\hline \multirow{6}{*}{$\begin{array}{l}\text { Переважно } \\
\text { генетичні причини } \\
\text { або вади розвитку }\end{array}$} & Епілептичні синдроми у дітей & Синдром Веста, синдром Леннокса-Гасто \\
\hline & $\begin{array}{l}\text { Прогресуючі міоклонічні } \\
\text { епілепсії }\end{array}$ & $\begin{array}{l}\text { Хвороба Унферріхта-Лундборга, дентато-рубро-паллідо- } \\
\text { льюісова атрофія, хвороба тілець Лафора, мітохондріальна } \\
\text { цитопатія, сіалідоз, нейрональний цероїдний ліпофусциноз }\end{array}$ \\
\hline & Нейрокутанні синдроми & $\begin{array}{l}\text { Туберозний склероз, нейрофіброматоз, синдром Стерджа- } \\
\text { Вебера }\end{array}$ \\
\hline & $\begin{array}{l}\text { Інші моногенні неврологічні } \\
\text { захворювання }\end{array}$ & $\begin{array}{l}\text { Синдром Ангельмана, лізосомні хвороби, } \\
\text { нейроакантоцитоз, органічні ацидурії та пероксисомні } \\
\text { хвороби, синдром Ретта, хвороба Вільсона }\end{array}$ \\
\hline & Хромосомні захворювання & $\begin{array}{l}\text { Синдром Дауна, синдром хромосоми 4р-, синдром } \\
\text { кільцевої хромосоми } 20\end{array}$ \\
\hline & $\begin{array}{l}\text { Уроджені вади розвитку } \\
\text { мозку }\end{array}$ & $\begin{array}{l}\text { Гемімегаленцефалія, фокальна кортикальна дисплазія, } \\
\text { агірія, пахігірія, агенезія мозолистого тіла, полімікрогірія }\end{array}$ \\
\hline \multirow{8}{*}{$\begin{array}{l}\text { Переважно набуті } \\
\text { причини }\end{array}$} & Склероз гіпокампа & Склероз гіпокампа \\
\hline & $\begin{array}{l}\text { Перинатальні ураження } \\
\text { головного мозку }\end{array}$ & $\begin{array}{l}\text { Неонатальні судоми, постнеонатальні судоми, дитячий } \\
\text { церебральний параліч }\end{array}$ \\
\hline & $\begin{array}{l}\text { Черепно-мозкова травма } \\
\text { мозку }\end{array}$ & $\begin{array}{l}\text { Відкрита травма голови, закрита травма голови, випадкові } \\
\text { травми голови у немовлят }\end{array}$ \\
\hline & Пухлина мозку & $\begin{array}{l}\text { Гліома, гангліогліома і гамартома, дизембріопластична } \\
\text { нейроепітеліальна пухлина, гіпоталамічна гамартома, } \\
\text { менінгіома }\end{array}$ \\
\hline & Нейроінфекції & $\begin{array}{l}\text { Вірусний менінгіт та енцефаліт, бактеріальний менінгіт і } \\
\text { абсцес, малярія, нейроцистицеркоз, туберкульоз, ВІл }\end{array}$ \\
\hline & $\begin{array}{l}\text { Цереброваскулярні } \\
\text { захворювання }\end{array}$ & $\begin{array}{l}\text { Крововилив у мозок або субарахноїдальний простір, } \\
\text { артеріовенозна мальформація, кавернозна гемангіома }\end{array}$ \\
\hline & Імунологічні захворювання & Енцефаліт Расмуссена, лімбічний енцефаліт \\
\hline & $\begin{array}{l}\text { Нейродегенеративні } \\
\text { захворювання }\end{array}$ & $\begin{array}{l}\text { Хвороба Альцгеймера, розсіяний склероз та демієлінізуючі } \\
\text { захворювання; гідроцефалія і поренцефалія }\end{array}$ \\
\hline
\end{tabular}

Примітка. * - модифіковано за [29].

Згідно з діагностичними стандартами Міжнародної протиепілептичної ліги, електроенцефалограма (ЕЕГ) є обов'язковим методом обстеження при епілепсії [9]. У діагностиці також використовується магнітно-резонансна томографія (МРТ), хоча під час проведення МРТ структурні зміни нервової тканини майже в половині випадків у хворих з чітко фокальними формами епілепсії не візуалізуються [19]. Такі ж труднощі у діагностиці можуть виникати і під час обстеження за допомогою ЕЕГ. Епілептиформні порушення не спостерігаються на електроенцефалограмі у 40-50 \% хво- рих після першого епілептичного нападу, а в 10 \% вони взагалі можуть не реєструватись впродовж хвороби [3, 15]. Незважаючи на це, ЕЕГ залишається основним методом у діагностиці епілепсії та моніторингу ефективності її лікування [21].

Для встановлення характеру нападу (епілептичний чи неепілептичний) у хворих пропонується проведення таких досліджень з урахуванням сучасних міжнародних рекомендацій [23]:

1. ЕЕГ-дослідження, яке повинно відповідати мінімальним стандартам Міжнародної протиепілептичної ліги (ILAE). 
Огляди літератури, оригінальні дослідження, погляд на проблему, ювілеї

2. Нейровізуалізація (МРТ головного мозку) для виявлення структурних змін нервової тканини. При негативному результаті МРТ-дослідження повинні проводитися в динаміці.

3. Ультразвукова доплерографія для диференціювання деяких пароксизмальних станів, а також скринінгу патології судинного русла.

4. Моніторинг артеріального тиску.

5. Електрокардіографія при підозрі на кардіогенні пароксизми.

6. Оцінка даних отоневрологічного обстеження для діагностики низки неепілептичних нападів.

7. Ендокринологічне обстеження за наявності показань.

8. Нейропсихологічне та психодіагностичне дослідження.

Незважаючи на значні досягнення у дослідженні цієї патології і розробці методів їі лікування, епілепсія, тим не менше, лишається значною медичною та соціальною проблемою [25]. Дві третини хворих з активною формою епілепсії контролюють свій стан за допомогою протиепілептичних препаратів (ПЕП), які мають широкий спектр побічних ефектів. Крім того, ПЕП лише пригнічують виникнення епілептичних нападів, а не лікують епілепсію як захворювання [5]. Усі ПЕП можна поділити на препарати першої $\mathrm{i}$ другої генерації (або традиційні) та третього покоління (або нові препарати), синтезовані після 1990 р. [4]. До традиційних ПЕП належать барбітурати - фенобарбітал, гексамідин, бензобарбітал, а також карбамазепін, фенітоїн, препарати вальпроєвої кислоти. До ПЕП третього покоління, які зареєстровані в Україні, належать ламотриджин, габапентин, леветирацетам, окскарбазепін, топірамат та інші. Нові ПЕП входять до групи ліків першої лінії вибору відповідно до певних типів епілептичних нападів і вважаються більш безпечними та з меншою кількістю побічних явищ [27].

Незважаючи на лікування навіть ПЕП нового покоління, приблизно у третини хворих на епілепсію $\epsilon$ неконтрольовані напади, тобто фармакорезистентне захворювання [26]. Лише незначній кількості пацієнтів із фармакорезистентною епілепсією можна рекомендувати оперативне втручання, яке бажано застосовувати не пізніше ніж через два роки від встановлення діагнозу з метою запобігання фармакорезистентності захворювання [12]. Більшості пацієнтів із симптоматичною фармакорезистентною епілепсією показане тривале, іноді довічне, використання ПЕП [7]. Досі дискутується питання, чи властива фармакорезистентність захворювання пацієнтам із самого початку, чи вона генетично детермінована, чи набута внаслідок тривалої неправильної терапії [17].
Останнім часом триває пошук методів лікування, які усувають причину патологічних нейронних розрядів і допомогли 6 прогнозувати можливий розвиток епілепсії після первинного пошкодження головного мозку [28]. Інші підходи у лікуванні епілепсії (стимуляція блукаючого нерва, кетогенна дієта, нейрохірургічні втручання) також здебільшого мають негативні наслідки [35].

Тому досі триває пошук оптимального лікування, яке 6 покращувало загальний стан хворого на епілепсію, а також допомогло мінімізувати інші, часто шкідливі, наслідки для соціальної адаптації такої дитини.

Перспективним та ефективним методом зниження частоти судомних нападів і покращення електроенцефалографічної картини у хворих на епілепсію може бути така терапевтична технологія, як транскраніальна мікрополяризація з використанням постійного струму малої сили (до 1 мА) $[8,32]$.

Дослідження механізмів, що лежать в основі впливу транскраніальної мікрополяризації на ЦНС, проведені за допомогою електрофізіологічних, електронно-мікроскопічних та інших методів, підтвердили можливість управління функціональним станом глибоких структур мозку (мигдалеподібного тіла та хвостатого ядра), які відіграють роль модуляторів його цілісної діяльності (судомної готовності мозку, рівня емоційної напруги або уваги тощо) [8].

Також було показано, що застосування транскраніальної мікрополяризації значно зменшувало спонтанні та епілептичні збуджувальні постсинаптичні струми на бікукуліновій in vitro моделі у мишей [10].

У своїй попередній роботі ми показали, що застосування транскраніальної мікрополяризації у дітей із симптоматичною епілепсією сприяло вираженому покращенню електроенцефалографічної картини: відзначалося зменшення вираженості епілептиформних змін, реєструвалося збільшення частоти та амплітуди альфа-та бета-ритмів, а також зменшення амплітуди і частоти дельта- і тета-ритмів [1]. Отримані нами дані свідчать про те, що додавання методу мікрополяризації у комплексне лікування хворих на епілепсію сприяє покращенню електроенцефалографічної картини і, відповідно, позитивно впливає на клінічний перебіг захворювання.

Було також показано, що під час процедури транскраніальної мікрополяризації підвищується нейронна активність як у зонах дії постійного струму, так і в ділянках, які безпосередньо не піддавалися впливу струму [34]. Підвищення нейронної активності супроводжується збільшенням збудливості в цих ділянках мозку і відповідними 
Огляди літератури, оригінальні дослідження, погляд на проблему, ювілеї

змінами їх метаболічної активності. Продемонстровано, що мікрополяризація позитивно впливає на ультраструктуру як самих нейронів, так і синаптичного апарату та гліальних клітин [6]. Відзначено також прискорення процесів регенерації та відновлення нейронної архітектури [34]. Було також показано, що транскраніальна мікрополяризація здатна суттєво впливати на обмін йонів кальцію, а також генерацію і акумуляцію цАМФ, які відіграють важливу роль в епілептогенезі $[16,22]$.

Незважаючи на значні успіхи в дослідженнях щодо створення нових засобів у лікуванні симптоматичної епілепсії, досі існують прогалини у знаннях щодо патофізіології епілепсії, а також нейрогенеративних механізмів і ендогенних нейропротекторів. Існує також потреба в дослідженні біомаркерів при епілепсії, які можуть бути використані нарівні з методами нейровізуалізації головного мозку [11]. Значні досягнення відбулися в дослідженні нейропластичності, і важливим завданням $\epsilon$ втілення цих результатів у клінічну практику. В основі пластичності головного мозку лежить здатність нервової системи реагувати на фізіологічні і патологічні зміни зовнішнього або/і внутрішнього середовища шляхом активації нейрогенезу, синаптогенезу, зміни нейрональних зв'язків та гліальних елементів $[18,20]$. Усе більшої популярності набувають підходи у лікуванні симптоматичної епілепсії, спрямовані на максимально можливе відновлення порушених функцій завдяки використанню потенціалу нейропластичності мозку [31, 34].

Висновки. Результати сучасних досліджень симптоматичної епілепсії розкривають багато перспективних напрямків і можливостей для корекції та лікування цієї патології.

Перспективи подальших досліджень полягають у визначенні безпечних та ефективних терапевтичних засобів, які застосовуються для лікування симптоматичної епілепсії.

\section{ЛІТЕРАТУРА}

1. Яценко К. В. Вплив комплексної терапії з використанням мікрополяризації на електроенцефалографічні показники у дітей, хворих на симптоматичну епілепсію / К. В. Яценко // Український неврологічний журнал. - 2017. - № 3. - С. 21-25.

2. A practical clinical definition of epilepsy / R. S. Fisher, C. Acevedo, A. Arzimanoglou [et al.] // Epilepsia. - 2014. Vol. 55, No. 4. - P. 475-482.

3. Abou-Khalil B. Atlas of EEG \& seizure semiology / B. Abou-Khalil, K. E. Misulis. - Elsevier, 2006. - 213 p.

4. Abraham S. Innovations in epilepsy management an overview / S. Abraham, M. Shaju // J. Pharm. Pharm. Sci. - 2013. - Vol. 16, No. 4. - P. 564-576.

5. Adult epilepsy / J. S. Duncan, J. W. Sander, S. M. Sisodiya, M. C. Walker // Lancet. -2006. - Vol. 367, No. 9516. P.1087-1100.

6. Akimova I. M. Ultrastructural changes in the cerebral cortex after transcranial micropolarization / I. M. Akimova, T. A. Novikova //Bull. Exp. Biol. Med.-1978.-Vol. 86, No. 6. - P. 1669-1672.

7. Alexopoulos A. V. Pharmacoresistant epilepsy: Definition and explanation / A. V. Alexopoulos // Epileptology. - 2013. - Vol. 1, No. 1. - P. 38-42.

8. Applications of transcranial direct current stimulation in children and pediatrics / G. N. Rivera-Urbina, M. A. Nitsche, C. M. Vicario [et al.] // Rev. Neurosci. - 2017. Vol. 28, No. 2. - P. 173-184.

9. Berg A. T. New concepts in classification of the epilepsies: entering 21st century / A. T. Berg, I. E. Scheffer // Epilepsia. - 2011. - Vol. 52, No. 6. - P. 1058-1062.

10. Chang W. P. Treatment with direct-current stimulation against cingulate seizure-like activity induced by 4-aminopyridine and bicuculline in an in vitro mouse model / W. P. Chang, H. C. Lu, B. C. Shyu // Exp. Neurol. - 2015. Vol. 265. - P. 180-192.
11. Diagnostic biomarkers of epilepsy / C. Sueri, S. Gasparini, S. Balestrini, A. Labate [et al.] // Curr. Pharm. Biotechnol. - 2018. - Vol. 19, No. 6. - P. 440-450.

12. Early surgical therapy for drug-resistant temporal lobe epilepsy: A randomized trial / J. Jr. Engel, M. P. McDermott, S.Wiebe [et al.] // JAMA. - 2012. - Vol. 307, No. 9. P. 922-930.

13. Epileptic seizures and epilepsy: Definition proposed by the International League Against Epilepsy (ILAE) and the International Bureau for Epilepsy (IBE) / R. S. Fisher, W. V. Boas, W. T. Blume [et al.] // Epilepsia. - 2005. - Vol. 46, No. 4. - P. 470-472.

14. Foldvary-Schaefer N. Textbook of clinical neurology (third edition) / N. Foldvary-Schaefer, E. Wyllie. - Elsevier Inc., 2007, P. 1213-1244.

15. Idiopathic generalized epilepsy: Phenotypic and electroencephalographic observations in a large cohort from South India / S. Sinha, M. N. Pramod, S. Dilipkumar, P. Satishchandra // Ann. Indian Acad. Neurol. - 2013. Vol. 16, No. 2. - P. 163-168.

16. Impact of transcranial direct current stimulation (tdcs) on neuronal functions / S. Das, P. Holland, M. A. Frens, O. Donchin // Front Neurosci. - 2016. - Vol. 10. - P. 550.

17. In vitro and in vivo experimental models employed in the discovery and development of antiepileptic drugs for pharmacoresistant epilepsy / G. Campos, A. Fortuna, A. Falcão, G. Alves // Epilepsy Res. - 2018. - Vol. 146. - P. 63-86.

18. Johansson B. B. Brain plasticity in health and disease / B. B. Johansson // Keio J. Med. - 2004. - Vol. 53, No. 4. - P. 231-246.

19. Koepp M. Neuroimaging: how far could it take us? / M. Koepp // Go for zero: International Epilepsy Summit, 25-26 May, 2012 : abstracts. - Madrid, 2012. - P. 19.

20. Mansvelder H. D. Synaptic plasticity in human cortical circuits: cellular mechanisms of learning and memory 
Огляди літератури, оригінальні дослідження, погляд на проблему, ювілеї

in the human brain? / H. D. Mansvelder, M. B. Verhoog, N. A. Goriounova // Curr. Opin. Neurobiol. - 2018. pii: S0959-4388(18)30069-2.

21. Miller J. W. Solving the dilemma of EEG misinterpretation / J. W. Miller, J. C. Henry // Neurology. - 2013. Vol. 80, No. 1. - P. 13-14.

22. Neurobiological effects of transcranial direct current stimulation: a review / L. F. Medeiros, I. C. de Souza, L. P. Vidor [et al.] // Front Psychiatry. - 2012. - Vol. 28, No. 3. - P. 110.

23. NICE Guideline CG 137 - The Epilepsies: diagnosis and management // 11 January 2012. Pages 99.

24. Novarino G. The sacred disease: the puzzling genetics of epileptic disorders / G. Novarino, S. T. Baek, J. G. Gleeson // Neuron. - 2013. - Vol. 80, No. 1. - P. 9-11.

25. Perucca E. Commentary: Epilepsy is a global problem / E. Perucca, A. Covanis, T. Dua // Epilepsia. - 2014. Vol. 55, No. 9. - P. 1326-1328.

26. Perucca E. Optimizing antiepileptic drug treatment in tumoral epilepsy / E. Perucca // Epilepsia. - 2013. Vol. 54, Suppl. 9. - P. 97-104.

27. Perucca P. Adverse effects of antiepileptic drugs / P. Perucca, F. G. Gilliam // Lancet. Neurology. -2012. - Vol. 11, No. 9. - P. 792-802.

28. Practice guideline update summary: Efficacy and tolerability of the new antiepileptic drugs I: Treatment of new-onset epilepsy: Report of the American Epilepsy Society and the Guideline Development, Dissemination, and Implementation Subcommittee of the American Academy of Neurology / A. M. Kanner, E. Ashman, D. Gloss [et al.] // Epilepsy Curr. - 2018. - Vol. 18, No. 4. - P. 260-268.

\section{REFERENCES}

1. Yatsenko, K.V. (2017). Vplyv kompleksnoi terapii z vykorystanniam mikropoliaryzatsii na elektroentsefalohrafichni pokaznyky u ditei, khvorykh na symptomatychnu epilepsiiu [Influence of complex treatment using transcranial direct current stimulation on the electroencephalographic parameters in children with symptomatic epilepsy]. Ukrainskyi nevrolohichnyi zhurnal - Ukranian Neurology Journal, 3, 21-25 [in Ukranian].

2. Fisher, R.S., Acevedo, C., Arzimanoglou, A., Bogacz, A., Cross, J.H., Elger, C.E., Engel, J.Jr. et al. (2014). A practical clinical definition of epilepsy. Epilepsia, 55, (4), 475-482.

3. Abou-Khalil, B., \& Misulis, K.E. (2006) Atlas of EEG \& seizure semiology. Elsevier.

4. Abraham, S., \& Shaju, M. (2013). Innovations in epilepsy management - an overview. J. Pharm. Pharm. Sci., 16, (4), 564-576.

5. Duncan, J.S., Sander, J.W., Sisodiya, S.M., \& Walker, M.C. (2006). Adult epilepsy. Lancet, 367, (9516), 1087-1100.

6. Akimova, I.M., \& Novikova, T.A. (1978). Ultrastructural changes in the cerebral cortex after transcranial micropolarization. Bull. Exp. Biol. Med., 86, (6), 1669-1672.

7. Alexopoulos, A.V. (2013). Pharmacoresistant epilepsy: Definition and explanation. Epileptology, 1, (1), 38-42.

8. Rivera-Urbina, G.N., Nitsche, M.A., Vicario, C.M., \& Molero-Chamizo, A. (2017). Applications of transcranial direct current stimulation in children and pediatrics. Rev. Neurosci., 28, (2), 173-184.
29. Shorvon S. D. The etiologic classification of epilepsy / S. D. Shorvon // Epilepsia. - 2011. - Vol. 52, No. 6. P. 1052-1057.

30. Sirven J. I. Epilepsy: A Spectrum disorder / J. I. Sirven // Cold Spring Harb Perspect Med. - 2015. - Vol. 5, No. 9. - P. a022848.

31. Sumner M. G. Neuroplasticity, epilepsy and neuroplasticity as a potential treatment for some forms of epilepsy / M. G. Sumner, P. A. Hwang // Clinical Neurophysiology. - 2013. - Vol. 124, Issue 6. - Page e3.

32. Ten minutes of $1 \mathrm{~mA}$ transcranial direct current stimulation was well tolerated by children and adolescents: Self-reports and resting state EEG analysis / V. Moliadze, S. Andreas, E. Lyzhko [et al.] // Brain Res. Bull. - 2015. Vol. 119, Pt A. - P. 25-33.

33. The epilepsies: The diagnosis and management of the epilepsies in adults and children in primary and secondary care // Pharmacological update of clinical guideline 20. - 2012. - P. 21-28.

34. Transcranial magnetic and direct current stimulation in children / M. Q. Hameed, S. C. Dhamne, R. Gersner [et al.] // Curr. Neurol. Neurosci. Rep. - 2017. - Vol. 17, No. 2. - P. 11-26.

35. Williams T. J. The role for ketogenic diets in epilepsy and status epilepticus in adults / T. J. Williams, M. C. Cervenka //Clinical Neurophysiology Practice.-2017.-Vol. 2.P. $154-160$

36. Wolf P. History of epilepsy: nosological concepts and classification / P. Wolf // Epileptic Disord. - 2014. Vol. 16, No. 3. - P. 261-269.

9. Berg, A.T., \& Scheffer, I.E. (2011). New concepts in classification of the epilepsies: entering 21st century. Epilepsia, 52, (6), 1058-1062.

10. Chang, W.P., Lu, H.C., \& Shyu B.C. (2015). Treatment with direct-current stimulation against cingulate seizurelike activity induced by 4-aminopyridine and bicuculline in an in vitro mouse model. Exp. Neurol., 265, 180-192.

11. Sueri, C., Gasparini, S., Balestrini, S., Labate, A., Gambardella, A., Russo, E., Leo, A. et al. (2018). Diagnostic biomarkers of epilepsy. Curr. Pharm. Biotechnol., 19, (6), 440-450.

12. Engel, J.Jr., McDermott, M.P., Wiebe, S., Langfitt, J.T., Stern, J.M., Dewar, S., Sperling, M.R. et al. (2012). Early surgical therapy for drug-resistant temporal lobe epilepsy: A randomized trial. JAMA, 307, (9), 922-930.

13. Fisher, R.S., van Emde Boas., W., Blume, W., Elger, C., Genton, P., Lee, P., \& Engel, J.Jr. (2005). Epileptic seizures and epilepsy: Definition proposed by the International League Against Epilepsy (ILAE) and the International Bureau for Epilepsy (IBE). Epilepsia, 46, (4), 470-472.

14. Foldvary-Schaefer, N., \& Wyllie, E. (2007). Textbook of clinical neurology (third edition). Elsevier Inc., 1213-1244.

15. Sinha, S,. Pramod, M.N., Dilipkumar, S., \& Satishchandra, P. (2013). Idiopathic generalized epilepsy: Phenotypic and electroencephalographic observations in a large cohort from South India. Ann. Indian Acad. Neurol., 16, (2), 163-168. 
Огляди літератури, оригінальні дослідження, погляд на проблему, ювілеї

16. Das, S., Holland, P., Frens, M.A., \& Donchin, O. (2016). Impact of transcranial direct current stimulation (TDCS) on neuronal functions. Front Neurosci., 10, 550.

17. Campos, G., Fortuna, A., Falcão, A., \& Alves, G. (2018). In vitro and in vivo experimental models employed in the discovery and development of antiepileptic drugs for pharmacoresistant epilepsy. Epilepsy Res., 146, 63-86.

18. Johansson, B.B. (2004). Brain plasticity in health and disease. Keio J. Med., 53, (4), 231-246.

19. Koepp, M. (2012). Neuroimaging: how far could it take us? Go for zero: International Epilepsy Summit, 2526 May, 2012: abstracts. Madrid.

20. Mansvelder, H.D., Verhoog, M.B., \& Goriounova, N.A. (2018). Synaptic plasticity in human cortical circuits: cellular mechanisms of learning and memory in the human brain? Curr. Opin. Neurobiol. pii: S0959-4388(18)30069-2.

21. Miller, J.W., \& Henry, J.C. (2013). Solving the dilemma of EEG misinterpretation. Neurology, 80, (1), 13-14.

22. Medeiros, L.F., de Souza, I.C., Vidor, L.P., de Souza, A., Deitos, A., Volz, M.S., Fregni, F. et al. (2012). Neurobiological effects of transcranial direct current stimulation: a review. Front Psychiatry, 28, (3), 110.

23. NICE Guideline CG 137 (2012). The Epilepsies: Diagnosis and Management.

24. Novarino, G., Baek, S.T., \& Gleeson, J.G. (2013). The sacred disease: the puzzling genetics of epileptic disorders. Neuron, 80, (1), 9-11.

25. Perucca, E., Covanis, A., \& Dua, T. (2014). Commentary: Epilepsy is a global problem. Epilepsia, 55, (9), 13261328.

26. Perucca, E. (2013). Optimizing antiepileptic drug treatment in tumoral epilepsy. Epilepsia, 54, (9), 97-104.

27. Perucca, P., \& Gilliam, F.G. (2012). Adverse effects of antiepileptic drugs. Lancet. Neurology, 11, (9), 792-802.
28. Kanner, A.M., Ashman, E., Gloss, D., Harden, C., Bourgeois, B., Bautista, J.F., Abou-Khalil, B. et al. (2018). Practice guideline update summary: Efficacy and tolerability of the new antiepileptic drugs I: Treatment of newonset epilepsy: Report of the American Epilepsy Society and the Guideline Development, Dissemination, and Implementation Subcommittee of the American Academy of Neurology. Epilepsy Curr., 18, (4), 260-268.

29. Shorvon, S.D. (2011). The etiologic classification of epilepsy. Epilepsia, 52, (6), 1052-1057.

30. Sirven, J.I. (2015). Epilepsy: A Spectrum disorder. Cold Spring Harb Perspect Med., 5, (9), a022848.

31. Sumner, M.G., \& Hwang, P.A. (2013). Neuroplasticity, epilepsy and neuroplasticity as a potential treatment for some forms of epilepsy. Clinical Neurophysiology, 124, (6), e3.

32. Moliadze, V., Andreas, S., Lyzhko, E., Schmanke, T., Gurashvili, T., Freitag, C.M., \& Siniatchkin, M. (2015). Ten minutes of $1 \mathrm{~mA}$ transcranial direct current stimulation was well tolerated by children and adolescents: Self-reports and resting state EEG analysis. Brain Res. Bull., 119, (Pt A), 25-33.

33. (2012). The epilepsies: The diagnosis and management of the epilepsies in adults and children in primary and secondary care. Pharmacological Update of Clinical Guideline, 20, 21-28.

34. Hameed, M.Q., Dhamne, S.C., Gersner, R., Kaye, H.L., Oberman, L.M., Pascual-Leone, A., \& Rotenberg, A. (2017). Transcranial magnetic and direct current stimulation in children. Curr. Neurol. Neurosci. Rep. 17, (2), 11-26.

35. Williams, T.J., \& Cervenka, M.C. (2017). The role for ketogenic diets in epilepsy and status epilepticus in adults. Clinical Neurophysiology Practice, 2, 154-160.

36. Wolf, P. (2014). History of epilepsy: nosological concepts and classification. Epileptic Disord., 16, (3), 261-269.

\title{
СИМПТОМАТИЧЕСКАЯ ЭПИЛЕПСИЯ: ПРИЧИНЫ ВОЗНИКНОВЕНИЯ И ПЕРСПЕКТИВНЫЕ МЕТОДЫ ЛЕЧЕНИЯ
}

\author{
Институт физиологии имени А. А. Богомольца НАН Украины, Киев \\ Неврологическая клиника доктора Яценко, Киев
}

РЕЗЮМЕ. Эпилепсия - одно из самых распространенных психоневрологических расстройств функционирования ЦНС, характеризующееся повторяющимися спонтанными эпилептическими припадками. Международная противоэпилептическая лига определяет эпилепсию как хроническое состояние мозга, которое характеризуется устойчивой склонностью вызывать эпилептические припадки и нейробиологическими, когнитивными, психологическими и социальными последствиями, а также определение эпилепсии требует возникновения хотя бы одного эпилептического приступа. Полиэтиологичность и необыкновенное разнообразие клинических проявлений эпилепсии определяют трудности в создании ее классификации. Несмотря на значительные научные достижения в неврологии, эпилепсия остается значительной медико-социальной проблемой и до сих пор нет ответов на ключевые вопросы о механизмах эпилептических припадков. Продолжается поиск оптимального лечения, которое бы улучшало общее состояние больного эпилепсией, а также помогло минимизировать другие, часто вредные, последствия для социальной адаптации такого человека.

Цель - проанализировать современные взгляды на проблему симптоматической эпилепсии и перспективные стратегии ее лечения.

Вывод. Результаты современных исследований симптоматической эпилепсии раскрывают ряд направлений и возможностей для коррекции и лечения этой патологии. Одним из перспективных и эффективных методов снижения частоты судорожных припадков и улучшения электроэнцефалографической картины у больных симптоматической эпилепсией может быть такая терапевтическая технология, как транскраниальная микрополяриза- 
Огляди літератури, оригінальні дослідження, погляд на проблему, ювілеї

ция. Добавление метода микрополяризации в комплексное лечение больных эпилепсией способствует улучшению электроэнцефалографической картины, и, соответственно, положительно влияет на клиническое течение заболевания. Дальнейшие исследования необходимы для определения безопасных и эффективных терапевтических средств, применяемых для лечения симптоматической эпилепсии.

КЛЮЧЕВЫЕ СЛОВА: симптоматическая эпилепсия; транскраниальная микрополяризация.

\title{
SYMPTOMATIC EPILEPSY: CAUSES AND PERSPECTIVE METHODS OF TREATMENT
}

@K. V. Yatsenko

\author{
O. Bohomolets Institute of Physiology of NAS of Ukraine, Kyiv \\ Dr. Yatsenko Neurological Clinic, Kyiv
}

SUMMARY. Epilepsy is one of the most common neuropsychiatric disorders of the central nervous system characterized by repeated spontaneous epileptic seizures. The International League against Epilepsy (ILAE) defines epilepsy as a chronic condition of the brain, which is characterized by an enduring predisposition to generate epileptic seizures and by the neurobiological, cognitive, psychological, and social consequences of this condition, and the definition of epilepsy requires the occurrence of at least one epileptic seizure. The polyetiology and the extraordinary diversity of the clinical manifestations of epilepsy determine the difficulties in its classification. Despite significant scientific advances in neurology, epilepsy remains a significant medical and social problem and there are still no answers to key questions about the mechanisms of epileptic seizures. The search for the optimal treatment that would improve the general condition of the patient with epilepsy, and also helped to minimize other, often harmful, consequences for the social adaptation of such a person, is still ongoing.

The aim - to analyze current views on the problem of symptomatic epilepsy and promising strategies for its treatment.

Conclusion. The results of modern studies on symptomatic epilepsy reveal a number of areas and opportunities for the correction and treatment of this pathology. One of the promising and effective methods of reducing the frequency of seizures and improving the electroencephalographic pattern in patients with symptomatic epilepsy may be transcranial direct current stimulation (tDCS). Adding the method of tDCS to the complex treatment of patients with epilepsy contributes to the improvement of the electroencephalographic pattern, and, accordingly, has a positive effect on the clinical course of the disease. Further research is needed to identify safe and effective therapeutic agents used to treat symptomatic epilepsy.

KEY WORDS: symptomatic epilepsy; transcranial direct current stimulation. 